\title{
Optimization of texture profile analysis parameters for commercial guava preserve
}

\author{
Mariele Antunes Vieira ${ }^{1}$, Maria Cecília Evangelista Vasconcelos Schiass ${ }^{1}$, Ana Clara Costa Dias ${ }^{2}$, \\ Paula Nogueira Curi ${ }^{3}$, Patrícia Aparecida Pimenta Pereira ${ }^{4 *}$ (D), \\ João De Deus Souza Carneiro ${ }^{1}$, Soraia Vilela Borges ${ }^{1}$, Fabiana Queiroz ${ }^{1}$
}

$10.1590 / 0034-737 X 202168060004$

\begin{abstract}
Motivated by the lack of studies that standardize and optimize the parameters of texture tests, this study aimed to determine the operating conditions for TPA to maximize the discrimination among samples of fruit preserves. The texture of the commercial guava preserves was evaluated using a texturometer. The Design Central Composite Rotational (DCCR) method was applied with four independent variables: speed test, sample volume, time between compression cycles and compression percentage. Only the compression percentage and test speed were significantly influenced by the texture parameters evaluated. The optimum operating region of TPA to better discriminate differences in texture parameters depended on the variable to be optimized, and for adhesiveness a compression of $75 \%$ and a compression speed of $0.23 \mathrm{~mm} \cdot \mathrm{s}$ are recommended. To detect differences among the samples for the parameters of cohesiveness, gumminess and resilience, the use of $15 \%$ compression and $2.59 \mathrm{~mm} \cdot \mathrm{s}$ speed is suggested. In both cases, one must employ the shortest time between two cycles and use a smaller sample size to save both the time of analysis and of the sample, respectively. For the parameters of hardness, elasticity and chewiness, optimal regions were not identified.
\end{abstract}

Keywords: design central composite rotational; food quality; testing machines.

\section{INTRODUCTION}

The textural quality of food can be assessed by instrumental or sensory analysis (Chen \& Opara, 2013), and several factors, such as amount of sugar, $\mathrm{pH}$ and acidity (Souza et al., 2014), may explain the variable texture of fruits, Furthermore, aspects such as moisture and chemical composition of the fruit can also change the texture, as they can affect the yield and therefore the moisture content of the processed product (Curi et al., 2017).

According to the International Organization for Standardization (ISO) (2009), texture is defined as "all the mechanical, geometrical and surface attributes of a product perceptible by means of mechanical, tactile and, where appropriate, visual and auditory receptors".
An instrumental texture evaluation is performed by quantitative techniques that are capable of simulating the mechanical movements of biting or chewing (Barrangou et al., 2006). Among the instrumental techniques, the texture profile analysis is widely used for generating multiple parameters that correlate well with sensory textural properties (Szczesniak, 1963a). Parameters such as test speed, percentage compression, time between two compression cycles and sample geometry are factors that influence the measurement of texture (Szczesniak, 1963b).

A wide variety of parameter values of the texture profile analysis (TPA) test can be found in various studies. Schiassi et al. (2019) used TPA to analyze samples of berry jelly, with a pretest, test, and post-test speed of $1.0 \mathrm{~mm} \cdot \mathrm{s}$, compression distance of $40.0 \mathrm{~mm}$ and first and second

\footnotetext{
Submitted on September 22 $2^{\text {th }}, 2020$ and accepted on February 14 $4^{\text {th }}, 2021$.

${ }^{1}$ Departamento de Ciência dos Alimentos, Universidade Federal de Lavras, Lavras, Minas Gerais, Brazil. marieleengalimentos@gmail.com; vasconcelosmariaufla@gmail.com; joaodedeus@ufla.br; sborges@dca.ufla.br; fqueiroz@ufla.br

${ }^{2}$ Programa de Pós Graduação em Saúde e Nutrição, Escola de Nutrição, Universidade Federal de Ouro Preto, Ouro Preto, Minas Gerais, Brazil. ana.clara2@aluno.ufop.edu.br

${ }^{3}$ Departamento de Agricultura, Universidade Federal de Lavras, Lavras, Minas Gerais, Brazil. paulanogueiracuri@yahoo.com.br

${ }^{4}$ Departamento de Alimentos, Escola de Nutrição, Universidade Federal de Ouro Preto, Ouro Preto, Minas Gerais, Brazil. patricia.pereira@ufop.edu.br

*Corresponding author: patricia.pereira@ufop.edu.br
} 
compressions of $10 \mathrm{~s}$. Curi et al. (2019) and Alves et al. (2019) analyzed fig jam and pepper jam respectively, with a test speed of $1.0 \mathrm{~mm} \cdot \mathrm{s}$, compression of $60 \%$ and a time between cycles of $10 \mathrm{~s}$.

The quality and reliability of laboratory tests depend on how the tests are conducted, and standardization is essential for the correct measurement of food parameters. Mechanisms of standardization are often critical to ensure repeatability and avoid variations in the parameters that may mask the true texture of the food.

Brazil is one of the largest producers of guava, and processing the guava into preserves represents an alternative way to add value to the fruit (Pereira et al., 2019). However, there are large differences in the physical and sensory characteristics among the brands of industrialized guava preserves found in the market, even among products from the same brand, and the standardization of these parameters is essential to maintain product quality and acceptability (Vitti et al., 2020).

Motivated by the lack of studies that standardize and optimize the parameters of texture tests in guava preserves, this study aimed to determine the conditions that must be employed in TPA to maximize the discrimination between guava preserve samples.

\section{MATERIAL AND METHODS}

\section{Materials}

Three guava preserve brands (designated A, B and C) bought locally in the town of Lavras, Minas Gerais, Brazil were evaluated. The A and B guava preserves were prepared with guava pulp, sugar, liquid sugar and citric acid, and $\mathrm{C}$ was prepared with guava and sugar. We chose to use three different brands because the texture is influenced by the composition of the formulations and by processing conditions.

\section{Texture profile analysis (TPA)}

A texturometer (TAXT2i, Stable Micro Systems Model, Goldaming, England) and a cylindrical stainless steel probe measuring $6 \mathrm{~mm}$ in diameter were used to evaluate the parameters of hardness, adhesiveness, elasticity, gumminess, cohesiveness, chewiness and resilience of the guava preserve.

The samples were cut into parallelepipeds measuring $2 \mathrm{~cm}$ in height with varying lengths and widths; thus, it was possible to obtain the volumes described in the experimental design (Table 1). Samples with $5 \mathrm{~cm}^{3}, 10 \mathrm{~cm}^{3}$ and $7.5 \mathrm{~cm}^{3}$ volumes were cut with a width and height of $2 \mathrm{~cm}$ and a length of $1.25 \mathrm{~cm}, 1.87 \mathrm{~cm}$ and $2.5 \mathrm{~cm}$, respectively. Samples with a $2.5 \mathrm{~cm}^{3}$ volume were $1 \mathrm{~cm}$ long, $1.25 \mathrm{~cm}$ wide and $2 \mathrm{~cm}$ high. Samples with a volume of $12.5 \mathrm{~cm}^{3}$ were $2.5 \mathrm{~cm}$ in length and width, and the height was standardized at $2 \mathrm{~cm}$.

\section{Experimental design and statistical analysis}

The Design Central Composite Rotational (DCCR) method with four independent variables (totaling 28 assays) was used to assess the effect of independent variables on the rheological properties of each sample. The independent variables were test speed $(\mathrm{mm} / \mathrm{s})$, sample volume $\left(\mathrm{cm}^{3}\right)$, time between compression cycles (s) and compression percentage (\%). The tests were performed in 10 replicates. Table 1 shows the experimental design for testing the levels of TPA and independent variables. The levels used in the present study were chosen through previous tests and data from the literature.

With the data obtained, we performed the analysis of the effects using the program Statistica 8.0, the surface generated responses and mathematical models of the TPA parameters influenced by the independent variables (test speed, time between two compressions, sample volume and compression percentage) were evaluated.

The effects of the factors (speed, time between two compression cycles, sample volume and compression percentage) were analyzed by linear, quadratic, and interaction of response (texture parameters) methods for each guava preserve, using the model described by equation 1 :

$Y=\beta_{0}+\beta_{1} x_{1}+\beta_{2} x_{2}+\beta_{3} x_{3}+\beta_{4} x_{4}+\beta_{11} x_{1}{ }^{2}+\beta_{22} x_{2}{ }^{2}+\beta_{33} x_{3}^{2}+$ $+\beta_{44} x_{4}^{2}+\beta_{12} x_{1} x_{2}+\beta_{13} x_{1} x_{3}+\beta_{14} x_{1} x_{4}+\beta_{23} x_{2} x_{3}+\beta_{24} x_{2} x_{4}++$ $\beta_{34} x_{4} x_{4}+e$

$\mathrm{Y}$ is the parameter studied, $\beta_{0}, \beta_{1}, \beta_{2}, \beta_{3}, \beta_{4}, \beta_{11}, \beta_{22}, \beta_{33}, \beta_{44}$, $\beta_{12}, \beta_{13}, \beta_{14}, \beta_{23}, \beta_{24}, \beta_{34}$ are the regression coefficients, $\mathrm{x}_{1 \text {, }}$ $\mathrm{x}_{2}, \mathrm{x}_{3}$ and $\mathrm{x}_{4}$ are the independent variables of test speed, time between two compression cycles, sample volume and compression percent, respectively, and $e$ is the experimental error.

To optimize the operating region with a higher discrimination capacity, we used variable D defined in equation 2, and the visualization of surfaces used to choose the optimal region of operation of the texturometer, which is equivalent to the region where there is a greater discrimination among samples (higher $\mathrm{D}$ values) according to the parameters of texture analysis.

$D=\left[\left(P_{A}-P_{B}\right)^{2}+\left(P_{A}-P_{C}\right)^{2}+\left(P_{B}-P_{C}\right)^{2}\right]^{1 / 2}$

$P_{A}, P_{B}$ and $P_{C}$ are the values of the texture parameters experimentals for texture of brands $A, B$ and $C$, respectively; the variable $D$ parameter correlated with the difference in texture parameters among the samples evaluated.

To check whether the optimized region provided greater discrimination among samples, the discrimination of samples in the optimized region with parameters was compared to a non-optimized region. We used the Tukey test (5\% significance) in the program Sisvar (Ferreira, 2014) for the TPA parameters in both regions. 


\section{RESULTS AND DISCUSSION}

\section{Evaluation of the effects on the parameters of the texture profile analysis (TPA)}

The significant variables $(\mathrm{p} \leq 0.05)$ for each model parameter were estimated using mathematical models (Table 2) for the texture parameters of different brands; significant parameters are typed in the highlighted (Table 2). A decision was made not to eliminate the non-significant coefficients from the complete models, as their removal would cause a decrease in the coefficient of determination $\left(\mathrm{R}^{2}\right)$, and the model would account for less than $70 \%$ of the total variance of the responses.

For the different brands, models for the parameters of hardness, elasticity, cohesiveness and resilience were used. The parameters of adhesiveness, gumminess and chewiness did not fit the model (the $\mathrm{F}_{\text {calculated }}$ was less than the $\mathrm{F}_{\text {tabulated }}$ in the analysis of variance) and therefore were not considered in the response surface determination.
For brand $\mathrm{B}$, gumminess and chewiness parameters did not fit the model (Table 2). However, for brand C, the parameters of adhesiveness, cohesiveness and resilience were used in the model. The other study variables (hardness, elasticity, gumminess and chewiness) did not fit the model.

The increases in the speed and percentage of the compression cycles and the hardness of brands A and B, produce a significant negative quadratic; so the paremeters have an optimum point, over which an increase provides lower hardeness. The region near the central point (1.41 $\mathrm{mm} \cdot \mathrm{s}$ and $45 \%$, respectively) of the parameter reaches its highest hardness value. This occurs because high rates of deformation of the sample cause breaks in the structure of the preserves. At low deformations, this response does not occur, and the higher deformations are associated with greater strength. According Peleg (2019), the use of different compressions will frequently result in very different degrees of hardness, meaning that the compres-

Table 1: Experimental design for texture profile analysis

\begin{tabular}{|c|c|c|c|c|c|c|c|c|}
\hline \multirow{2}{*}{ Essays } & \multicolumn{4}{|c|}{ Coded Variables } & \multicolumn{4}{|c|}{ Real Variables } \\
\hline & $\mathbf{x}_{1}$ & $x_{2}$ & $\mathbf{x}_{3}$ & $\mathbf{x}_{4}$ & $\mathbf{X}_{1}$ & $\mathbf{X}_{2}$ & $\mathbf{X}_{3}$ & $X_{4}$ \\
\hline 1 & -1 & -1 & -1 & -1 & 0.83 & 5 & 5 & 30 \\
\hline 2 & +1 & -1 & -1 & -1 & 2 & 5 & 5 & 30 \\
\hline 3 & -1 & +1 & -1 & -1 & 0.83 & 10 & 5 & 30 \\
\hline 4 & +1 & +1 & -1 & -1 & 2 & 10 & 5 & 30 \\
\hline 5 & -1 & -1 & +1 & -1 & 0.83 & 5 & 10 & 30 \\
\hline 6 & +1 & -1 & +1 & -1 & 2 & 5 & 10 & 30 \\
\hline 7 & -1 & +1 & +1 & -1 & 0.83 & 10 & 10 & 30 \\
\hline 8 & +1 & +1 & +1 & -1 & 2 & 10 & 10 & 30 \\
\hline 9 & -1 & -1 & -1 & +1 & 0.83 & 5 & 5 & 60 \\
\hline 10 & +1 & -1 & -1 & +1 & 2 & 5 & 5 & 60 \\
\hline 11 & -1 & +1 & -1 & +1 & 0.83 & 10 & 5 & 60 \\
\hline 12 & +1 & +1 & -1 & +1 & 2 & 10 & 5 & 60 \\
\hline 13 & -1 & -1 & +1 & +1 & 0.83 & 5 & 10 & 60 \\
\hline 14 & +1 & -1 & +1 & +1 & 2 & 5 & 10 & 60 \\
\hline 15 & -1 & +1 & +1 & +1 & 0.83 & 10 & 10 & 60 \\
\hline 16 & +1 & +1 & +1 & +1 & 2 & 10 & 10 & 60 \\
\hline 17 & -2 & 0 & 0 & 0 & 0.23 & 7.5 & 7.5 & 45 \\
\hline 18 & +2 & 0 & 0 & 0 & 2.59 & 7.5 & 7.5 & 45 \\
\hline 19 & 0 & -2 & 0 & 0 & 1.41 & 2.5 & 7.5 & 45 \\
\hline 20 & 0 & +2 & 0 & 0 & 1.41 & 12.5 & 7.5 & 45 \\
\hline 21 & 0 & 0 & -2 & 0 & 1.41 & 7.5 & 2.5 & 45 \\
\hline 22 & 0 & 0 & +2 & 0 & 1.41 & 7.5 & 12.5 & 45 \\
\hline 23 & 0 & 0 & 0 & -2 & 1.41 & 7.5 & 7.5 & 15 \\
\hline 24 & 0 & 0 & 0 & +2 & 1.41 & 7.5 & 7.5 & 75 \\
\hline 25 & 0 & 0 & 0 & 0 & 1.41 & 7.5 & 7.5 & 45 \\
\hline 26 & 0 & 0 & 0 & 0 & 1.41 & 7.5 & 7.5 & 45 \\
\hline 27 & 0 & 0 & 0 & 0 & 1.41 & 7.5 & 7.5 & 45 \\
\hline 28 & 0 & 0 & 0 & 0 & 1.41 & 7.5 & 7.5 & 45 \\
\hline
\end{tabular}

$\mathrm{x}_{1}$ : test speed $(\mathrm{mm} \cdot \mathrm{s}) ; \mathrm{x}_{2}$ : time $(\mathrm{s})$ between two compressions; $\mathrm{x}_{3}$ : sample volume $\left(\mathrm{cm}^{3}\right) ; \mathrm{x}_{4}:$ compression percentage $(\%)$. 
sion caused by chewing affects the perception of food hardness.

The TPA hardness test is the peak force during the first cycle in which the sample is compressed (Alvarez et al., 2002). According to Rosenthal (2010), breakage of the material occurs when the peak of the second compression is smaller than the first peak, which indicates the occurrence of a breakdown of the internal structure.

The variable $x_{2}$ (time between compression cycles) did not significantly influence the hardness; none of the variables analyzed were expected to significantly influence this parameter because hardness is calculated in the first compression cycle. The time between compression cycles can influence the calculation of parameters that depend on the second compression cycle (cohesiveness, springiness, gumminess and chewiness) of TPA, as the second cycle permits recovery of the resilient structure of the sample from the first compression if it is not high enough to rupture the cellular structure of the food.

Rosenthal (2010) examined how the modification of the TPA parameters influences the properties of a starchglycerol gel. For deformations ranging from $25 \%$ to $90 \%$, an exponential relationship between hardness and compression percent was observed. The hardness increased with the increasing compression percentage up to $90 \%$; above a $90 \%$ deformation, a rupture of the gel during compression was observed, causing a decrease in the first peak strength.

Table 2: Estimation of models for TPA parameters with significant effects for brands A, B and C

\begin{tabular}{|c|c|c|}
\hline Parameter & Model & $\mathbf{R}^{2}$ \\
\hline \multicolumn{3}{|c|}{ Brand A } \\
\hline $\begin{array}{l}\text { Hardness } \\
\text { (N) }\end{array}$ & $\begin{array}{l}Y=2.42+0.09 x_{1}-0.33 x_{1}^{2}+0.06 x_{2}-0.13 x_{2}^{2}+0.16 x_{3}- \\
0.11 x_{3}^{2}-0.03 x_{4}-0.3 x_{4}^{2}-0.16 x_{1} x_{2}+0.02 x_{1} x_{3}+ \\
0.06 x_{1} x_{4}-0.08 x_{2} x_{3}+0.22 x_{2} x_{4}-0.21 x_{3} x_{4}\end{array}$ & 0.74 \\
\hline $\begin{array}{l}\text { Springiness } \\
(\mathrm{mm})\end{array}$ & $\begin{array}{l}Y=\mathbf{0 . 8 8}-\mathbf{0 . 3 5} \boldsymbol{x}_{1}+0.001 x_{1}^{2}-0.02 x_{2}+0.01 x_{2}^{2}+ \\
0.02 x_{3}-0.01 x_{3}^{2}-0.029 x_{4}-\mathbf{0 . 0 8} \boldsymbol{x}_{4}^{2}-0.07 x_{1} x_{2}- \\
0.001 x_{1} x_{3}-0.002 x_{1} x_{4}-0.07 x_{2} x_{3}+0.02 x_{2} x_{4}-0.02 x_{3} x_{4}\end{array}$ & 0.75 \\
\hline $\begin{array}{l}\text { Cohesiveness } \\
\text { (dimensionless) }\end{array}$ & $\begin{array}{l}Y=\mathbf{0 . 3 4}+0.05 x_{1}+0.07 x_{1}^{2}+0.01 x_{2}+0.001 x_{2}^{2}- \\
0.03 x_{3}+0.01 x_{3}^{2}-\mathbf{0 . 1 3} x_{4}+\mathbf{0 . 7} \boldsymbol{x}_{4}^{2}+0.03 x_{1} x_{2}+ \\
0.02 x_{1} x_{3}-0.02 x_{1} x_{4}-0.03 x_{2} x_{3}-0.02 x_{2} x_{4}+0.05 x_{3} x_{4}\end{array}$ & 0.86 \\
\hline Resilience & 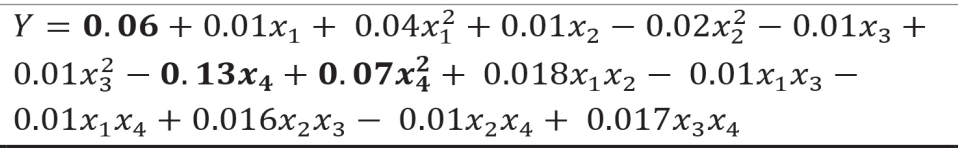 & 0.96 \\
\hline \multicolumn{3}{|c|}{ Brand B } \\
\hline $\begin{array}{l}\text { Hardness } \\
\text { (N) }\end{array}$ & $\begin{array}{l}Y=1.99-0.02 x_{1}-0.23 x_{1}^{2}+0.05 x_{2}+0.05 x_{2}^{2}+0.12 x_{3}- \\
0.016 x_{3}^{2}-0.09 x_{4}-0.25 x_{4}^{2}-0.11 x_{1} x_{2}-0.09 x_{1} x_{3}+ \\
0.02 x_{1} x_{4}-0.14 x_{2} x_{3}-0.01 x_{2} x_{4}+0.021 x_{3} x_{4}\end{array}$ & 0.81 \\
\hline $\begin{array}{c}\text { Adhesiveness } \\
\qquad(\mathrm{N} \cdot \mathrm{s})\end{array}$ & $\begin{array}{l}Y=-1.31+0.57 x_{1}-0.25 x_{1}^{2}+0.08 x_{2}+0.15 x_{2}^{2}- \\
0.04 x_{3}-0.01 x_{3}^{2}-1.36 x_{4}-0.25 x_{4}^{2}+0.11 x_{1} x_{2}- \\
0.03 x_{1} x_{3}+0.36 x_{1} x_{4}-0.02 x_{2} x_{3}+0.06 x_{2} x_{4}-0.09 x_{3} x_{4}\end{array}$ & 0.96 \\
\hline $\begin{array}{c}\text { Springiness } \\
(\mathrm{mm})\end{array}$ & 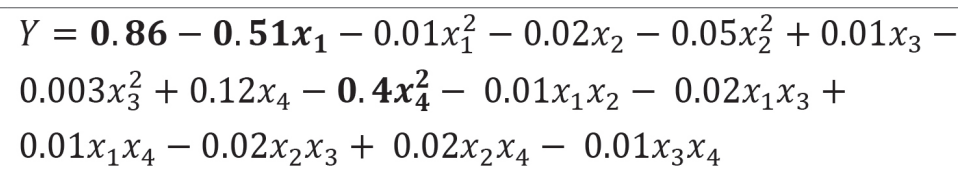 & 0.9 \\
\hline $\begin{array}{l}\text { Cohesiveness } \\
\text { (dimensionless) }\end{array}$ & 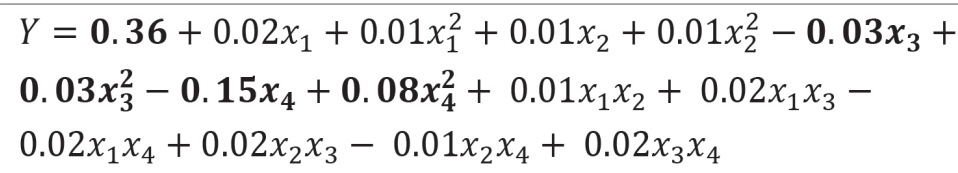 & $0.8 !$ \\
\hline Resilence & $\begin{array}{l}Y=\mathbf{0 . 0 6}+0.02 x_{1}+0.01 x_{1}^{2}+0.01 x_{2}+0.02 x_{2}^{2}-0.01 x_{3}+ \\
0.01 x_{3}^{2}-\mathbf{0 . 1 5} x_{4}+\mathbf{0 . 0 7} x_{4}^{2}+0.01 x_{1} x_{2}+0.02 x_{1} x_{3}- \\
0.02 x_{1} x_{4}+0.01 x_{2} x_{3}-0.01 x_{2} x_{4}+0.01 x_{3} x_{4}\end{array}$ & 0.9 \\
\hline
\end{tabular}

$\mathrm{x}_{1}$ : speed test, $\mathrm{x}_{2}$ : time between compressions; $\mathrm{x}_{3}$ : sample volume; $\mathrm{x}_{4}$ : percentage of compression. 
According to Pons \& Fiszman (1996), increased compression speeds generally lead to an increase in hardness because at lower compression velocities, the sample has a longer time to relax and dissipate the applied force. We observed this behavior in the model adjusted to the hardness of samples A and B (Table 2), where the negative coefficient of the quadratic test probe speed enhanced the rigidity of the guava until reaching a maximum point.

Springiness is a perception of "rubber" in the mouth (Huang et al., 2007). The Exponent Lite Express software calculates springiness as the ratio between the time taken to reach the peak force in the second compression cycle to the time spent in the first compression cycle. For the springiness of samples A and B, there were significant negative linear and quadratic effects in the velocity and compression percentage, respectively, indicating that the elasticity of the guava preserve increased with increasing compression percentages in the samples and reached a maximum level. There was a linear decrease of this TPA parameter with increased speed. The guava preserve sample $\mathrm{C}$ was not associated with a significant regression model for this TPA parameter. According to Rosenthal (2010), for starch gels and glycerol, the elasticity increases with progressive increases of up to $75 \%$ compression before stabilizing. In the study by Pons \& Fiszman (1996), in the ê-carrageenan/LBG and gellan systems the waiting time had an important effect on the measurement of springiness. As the degree of compression increased, significantly lower values $(p<0.05)$ were recorded for the springiness parameter. This was due to the fact that at higher compression levels the potential damage to the gel structure was greater and recovery was less likely, indicating that deformation caused structural weakening.

Adhesiveness is the work necessary to overcome the attractive forces between the surface of the food and other objects, in this case, the probe (Pereira et al., 2013); this parameter corresponds to the negative area of the graph force versus the time of the first TPA cycle. The value of adhesiveness for guava preserves sample B was influenced positively and negatively by the velocity squared test. The percentage of compression values were significantly negative in the linear model and were positive for the adhesiveness of the same sample. We observed an positive interaction between the speed test and the percentage of compression. The adhesiveness of sample C showed significantly positive for the linear term for speed and significabtly negative for the sample volume and linear compression. Significant interactions between these factors were observed; the interaction between the speed and sample volume was positive, while the interaction between the volume and percentage of compression was negative. The value of the adhesiveness of sample A was not influenced by the levels of the parameters used in the TPA. According to Pons \& Fiszman (1996), the contribution of the adhesiveness parameter to the TPA is low due to problems associated with the measurement, especially for sticky foods, which stick to the surface of the probe during the upward movement of the first compression cycle. It has been reported by Dobraszczyk (1997) that "single-point" methods for assessing adhesiveness have limitations, owing to the viscoelastic properties of most food products.

The cohesiveness is the rate at which the material is disintegrated under the mechanical action being performed and is determined by calculating the ratio between the area of the first and second compression cycles (Pereira et al., 2013). The linear effects (positive) and quadratic compression percentage (negative) influenced the cohesiveness values for all the samples. This result indicates that for higher compression percentages, lower values for sample cohesiveness were obtained because of the existence of a linear effect in the adjusted model, possibly due to a greater force upon the material in first cycle by increasing the compression distance. A similar result was obtained by Rosenthal (2010). Fogaça et al. (2017) reported in their studies with cheese that cohesiveness is not influenced by the way the product is cut, but by the compression degree, since it has isotropic behavior. Alvarez et al. (2002) affirm that the greater the deformation percentage, the greater will be the fragmentation of the specimens tested. The above is desirable so that the chewing process would be imitated, although certain variables, such as springiness or cohesiveness, may turn out to be physically directionless. The use of compression degrees above to $85 \%$ may cause fragmentation of the material, causing anisotropic characteristics become imperceptible for certain variables, such as chewiness.

Resilience is a measure of how much the sample returns after the mechanical action, and its value is determined by the area of stress versus the strain curve of the linear region. This parameter does not belong in conventional texture profile analysis, but TPA has been applied to allow closer examination of the elastic recovery of the sample, and greater elastic behavior (property of a solid material) indicates higher resilience (Pereira et al., 2013). According Jeguirim et al. (2010) the resilience is correlated with the surface sensory attributes.

The parameters of cohesiveness and resilience were very similar in all of the brands tested regarding the effects of the independent variables and the response surfaces. For resilience, no significant influence of sample size was observed, as was the case with cohesiveness. However, for both parameters, there were significant negative linear effects and a positive quadratic effect of compression rate 
in the quadratic model. Similar results were obtained by Huson \& Maxwell (2006) which verified that the increase in the compression rate increased the resilience.

Data from this study show that the values of the variables obtained by TPA are influenced by variations in test parameters except for the time between two cycles and the sample size. Thus, to compare similar gels studied by different authors, the parameters used in the analysis must be similar, especially the test speed and percentage of compression.

\section{Optimization of the independent variables in the texture profile analysis (TPA)}

Design Central Composite Rotational (DCCR) analysis was applied to identify the optimal operating region of the parameters that best discriminates the samples, using variable $\mathrm{D}$ as the dependent variable (Equation 1) to measure the difference between the measured values for the different texture parameters. The mathematical models fitted to equation 2 are shown in Table 3, where the significant coefficients ( $\mathrm{p}$ d" 0.05 ) are highlighted.

The time between two cycles $\left(\mathrm{x}_{2}\right)$ and sample volume $\left(\mathrm{x}_{3}\right)$, with a constant height tested at different levels did not significantly influence the texture parameter values. For the parameters of hardness, springiness and chewiness, the values of $\mathrm{D}$ were not influenced by the parameters of the TPA test; i.e., for these texture variables, the entire range of tested values of the TPA parameters did not differ in the ability to discriminate between samples.

Figure 1 shows the response surface analysis for variable $\mathrm{D}$, including the responses for adhesiveness, cohesiveness, gumminess and resilience generated by the models described in Table 3.

The effect of the percentage of compression and the velocity test on the texture parameters (adhesiveness, cohesiveness, gumminess and resilience) can be observed in these figures. The greatest differences occurred for

Table 3: Estimated models for variable D of the samples for the discrimination of texture parameters

\begin{tabular}{|c|c|c|}
\hline Parameter & Model & $\mathbf{R}^{2}$ \\
\hline $\begin{array}{l}\text { Adhesiveness } \\
\qquad(\mathrm{N} \cdot \mathrm{s})\end{array}$ & $\begin{array}{l}Y=\mathbf{0 . 8 8}-\mathbf{0 . 8 1} x_{1}+\mathbf{0 . 8 8} x_{1}^{2}+0.11 x_{2}+0.11 x_{2}^{2}-0.11 x_{3}-0.1 x_{3}^{2}+ \\
\mathbf{0 . 5 1} x_{\mathbf{4}}+0.22 x_{4}^{2}-0.01 x_{1} x_{2}-0.32 x_{1} x_{3}-0.49 x_{1} x_{4}-0.29 x_{2} x_{3}- \\
0.09 x_{2} x_{4}-0.28 x_{3} x_{4}\end{array}$ & 0.73 \\
\hline $\begin{array}{c}\text { Cohesiveness } \\
\text { (dimensionless) }\end{array}$ & $\begin{array}{l}Y=\mathbf{0 . 0 4}+\mathbf{0 . 0 6} x_{1}+\mathbf{0 . 0 9} x_{1}^{2}-0.01 x_{2}-0.01 x_{2}^{2}+0.001 x_{3}+ \\
0.02 x_{3}^{2}-0.03 x_{4}-0.01 x_{4}^{2}+0.03 x_{1} x_{2}+0.04 x_{1} x_{3}-0.02 x_{1} x_{4}- \\
0.03 x_{2} x_{3}-0.001 x_{2} x_{4}-0.04 x_{3} x_{4}\end{array}$ & 0.70 \\
\hline \multirow{2}{*}{$\begin{array}{l}\text { Gumminess } \\
(\mathrm{N} \cdot \mathrm{mm})\end{array}$} & $Y=49.03+12.5 x_{1}-1.23 x_{1}^{2}+5.29 x_{2}-3.71 x_{2}^{2}+2.24 x_{3}-$ & \\
\hline & $\begin{array}{l}5.12 x_{3}^{2}-17.59 x_{4}-0.83 x_{4}^{2}-3.49 x_{1} x_{2}-4.11 x_{1} x_{3}-4.04 x_{1} x_{4}- \\
5.14 x_{2} x_{3}-3.03 x_{2} x_{4}-6.46 x_{3} x_{4}\end{array}$ & 0.67 \\
\hline Resilience & 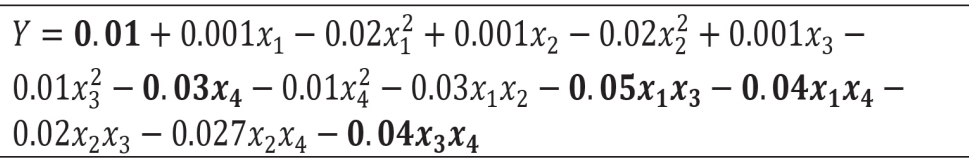 & 0.76 \\
\hline
\end{tabular}

$\mathrm{x}_{1}$ : speed probe, $\mathrm{x}_{2}$ : time between compressions; $\mathrm{x}_{3}$ : sample volume; $\mathrm{x}_{4}$ : percentage of compression.

Table 4: Tukey test results for the TPA parameters for different brands of guava preserve obtained using non-optimized TPA test operating conditions

\begin{tabular}{lccc}
\hline \multirow{2}{*}{ Parameter } & \multicolumn{3}{c}{ Brands } \\
\cline { 2 - 4 } & $\mathbf{A}$ & $\mathbf{B}$ & $\mathbf{C}$ \\
\hline Hardness (N) & $0.70 \pm 0.32^{\mathrm{a}}$ & $1.19 \pm 0.58^{\mathrm{a}}$ & $1.26 \pm 0.51^{\mathrm{a}}$ \\
Adhesiveness (N·s) & $-0.26 \pm 1.93^{\mathrm{a}}$ & $-0.09 \pm 1.51^{\mathrm{a}}$ & $-0.04 \pm 0.64^{\mathrm{a}}$ \\
Springiness (mm) & $0.72 \pm 0.14^{\mathrm{a}}$ & $0.73 \pm 0.14^{\mathrm{a}}$ & $0.79 \pm 0.12^{\mathrm{a}}$ \\
Cohesiveness (dimensionless) & $27.15 \pm 5.80^{\mathrm{a}}$ & $43.53 \pm 7.23^{\mathrm{a}}$ & $45.06 \pm 10.05^{\mathrm{a}}$ \\
Gumminess (N·mm) & $0.35 \pm 0.18^{\mathrm{a}}$ & $0.38 \pm 0.17^{\mathrm{a}}$ & $0.39 \pm 0.14^{\mathrm{a}}$ \\
Chewiness (N·mm) & $34.13 \pm 28.23^{\mathrm{a}}$ & $58.86 \pm 33.64^{\mathrm{a}}$ & $63.73 \pm 15.36^{\mathrm{a}}$ \\
Resilience & $0.11 \pm 0.15^{\mathrm{a}}$ & $0.15 \pm 0.17^{\mathrm{a}}$ & $0.26 \pm 0.14^{\mathrm{a}}$
\end{tabular}

Mean \pm value standard deviation $(n=5)$; Means followed by the same letters in line do not differ according to the Tukey test at a $5 \%$ probability. 
adhesiveness in the regions of high and low compression percentage test speeds. For the other parameters (cohesiveness, gumminess and resilience), regions where there were major differences between the samples corresponded to lower compression percentage levels and higher speed tests.
The texture profile analysis simulates chewing and thus requires large deformations (20\% to 50\%) (Huang et al., 2007). According to various authors, these deformations cause the sample to collapse and are not suitable for the calculation of some parameters, such as adhesiveness (Pons \& Fiszman, 1996; Dobraszczyk, 1997), because

Table 5: Tukey test results for the TPA parameters of texture profile analysis of different brands of guava preserve obtained using optimized TPA operating conditions

\begin{tabular}{lccc}
\hline \multirow{2}{*}{ Parameter } & \multicolumn{3}{c}{ Brands } \\
\cline { 2 - 4 } & A & B & C \\
\hline Hardness (N) & $1.25 \pm 0.22^{\mathrm{a}}$ & $1.25 \pm 0.54^{\mathrm{a}}$ & $0.70 \pm 0.27^{\mathrm{b}}$ \\
Adhesiveness (N·s) & $-4.42 \pm 1.79^{\mathrm{a}}$ & $-4.04 \pm 1.23^{\mathrm{a}}$ & $-1.39 \pm 0.69^{\mathrm{b}}$ \\
Springiness (mm) & $0.91 \pm 0.12^{\mathrm{a}}$ & $0.88 \pm 0.04^{\mathrm{a}}$ & $0.76 \pm 0.02^{\mathrm{b}}$ \\
Cohesiveness (dimensionless) & $44.40 \pm 5.22^{\mathrm{a}}$ & $43.91 \pm 5.23^{\mathrm{a}}$ & $27.06 \pm 3.57^{\mathrm{b}}$ \\
Gumminess (N·mm) & $0.35 \pm 0.01^{\mathrm{a}}$ & $0.36 \pm 0.01^{\mathrm{a}}$ & $0.38 \pm 0.00^{\mathrm{b}}$ \\
Chewiness (N·mm) & $40.65 \pm 8.40^{\mathrm{a}}$ & $38.72 \pm 3.98^{\mathrm{a}}$ & $20.45 \pm 5.78^{\mathrm{b}}$ \\
Resilience & $0.02 \pm 0.05^{\mathrm{a}}$ & $0.07 \pm 0.05^{\mathrm{a}}$ & $0.16 \pm 0.03^{\mathrm{b}}$ \\
\hline
\end{tabular}

Mean \pm value standard deviation $(n=5)$; Means followed by the same letters in line do not differ according to the Tukey test at $5 \%$ probability.

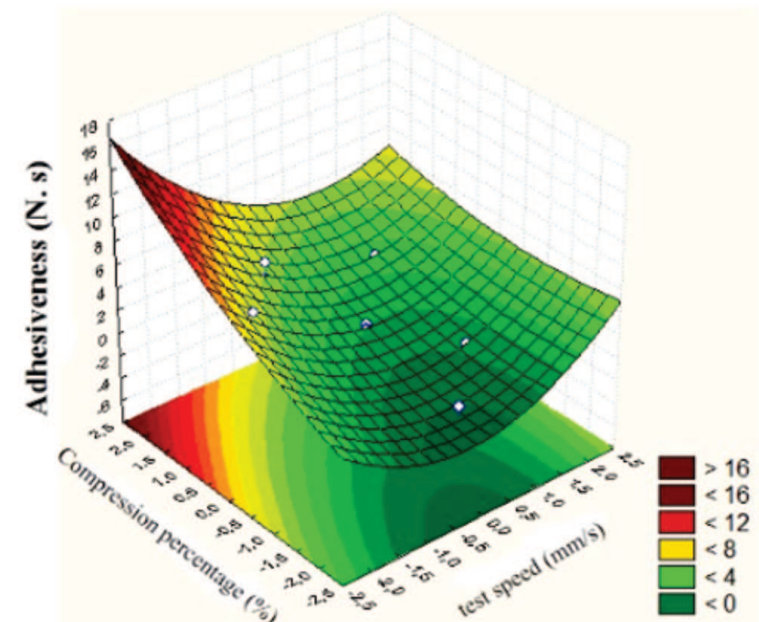

(a)

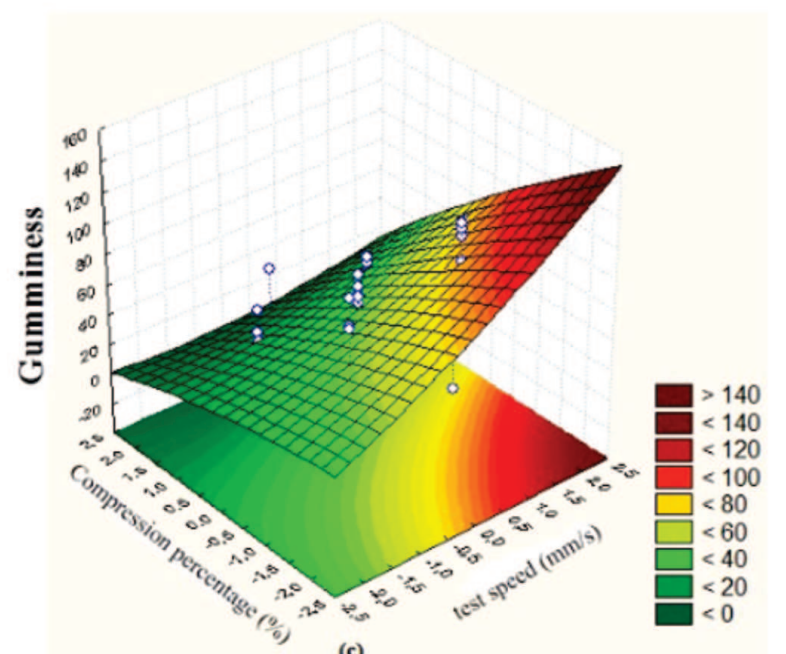

(c)
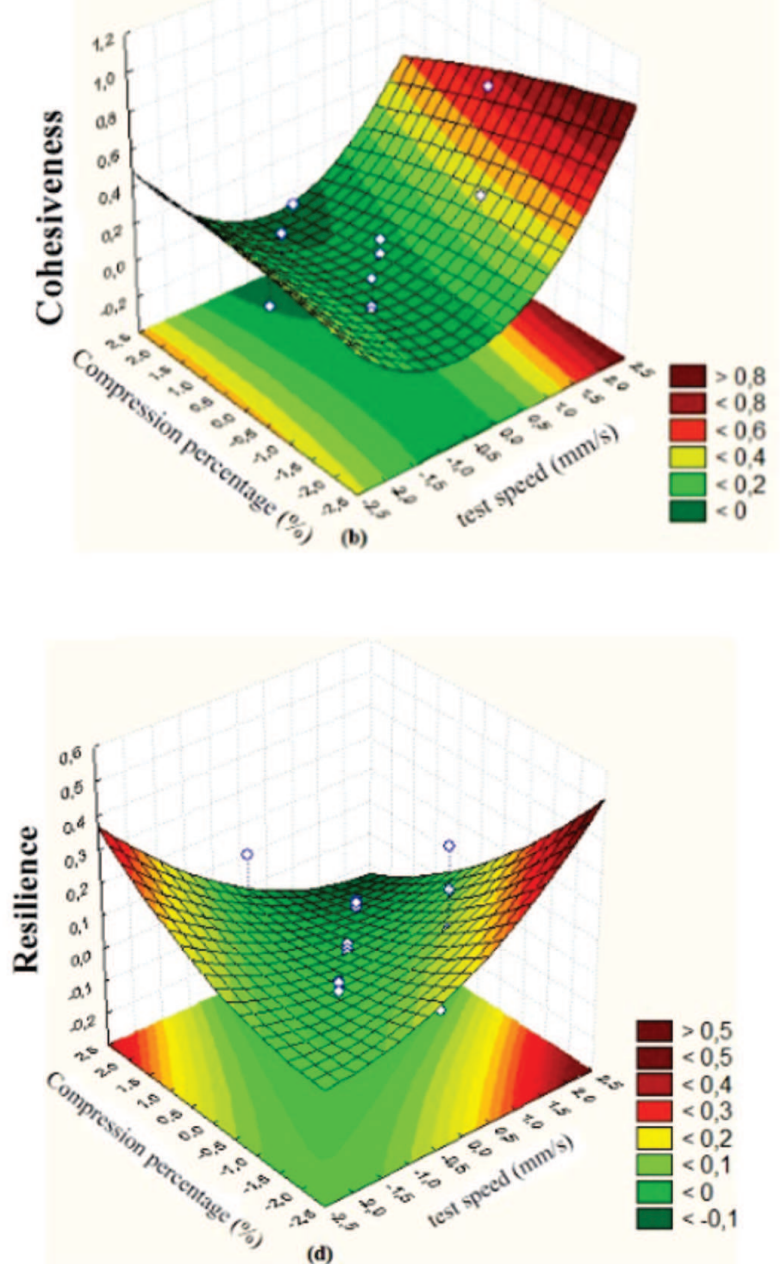

Figure 1: Surface Response Variable D: (a) adhesiveness, (b) cohesiveness, (c) gumminess and (d) resilience. 
this parameter is a characteristic of surface-dependent effects of the combined forces of adhesion and cohesion (Adhikari et al., 2001; Huang et al., 2007; Besbes et al., 2009).

Thus, the operating region where a greater discrimination of the texture parameters studied can be obtained depends on the parameter being analyzed. For adhesiveness, the regions with the highest compression compression percentages $(75 \%)$ and lowest velocities $(0.23 \mathrm{~mm} \cdot \mathrm{s})$ showed the greatest discrimination, while the parameters of cohesiveness, gumminess and resilience corresponded to regions of low compression percentages $(15 \%)$ and high speeds $(2.59 \mathrm{~mm} \cdot \mathrm{s})$. The time between two cycles variable and the sample size had no significant effect on detecting differences in texture parameters among samples, which suggests that in the implementation of TPA, the use of shorter cycles between two samples and smaller sample sizes saved both analysis time and sample, respectively.

\section{Evaluation of optimization of the independent variables in the texture profile analysis (TPA)}

Table 4 presents the average Tukey test at a $5 \%$ significance level, including the data obtained in the texture profile analysis with non-optimized tests (tests 2 , 4,6 and 8 for adhesiveness; assays 9, 11, 13, 14 and 15 for cohesiveness, gumminess and resilience; assays 7, 8, 15 and 16 for hardness, elasticity and chewiness) of the experimental design described in Table 1 . Table 5 shows the same test medium and the same significance level, but with the optimized data obtained from the tests (tests 9, 11, 13 and 15 for adhesiveness; assays 2, 4, 6 and 8 for cohesiveness, gumminess and resilience; assays 1, 2, 9 and 10 for hardness, springiness and chewiness).

All of the parameters provided by the texture profile analysis for samples $\mathrm{A}$ and $\mathrm{B}$ differed from $\mathrm{C}$ after the operating conditions were optimized. According to the non-optimized data, there were no significant differences between any of the TPA parameters tested for the brands studied. Thus, we conclude that when the objective is to study changes in the sample over time during storage or to discriminate samples of different formulations, an optimization of the operating region of the TPA can provide a greater discrimination of the samples for the parameters studied.

\section{CONCLUSION}

The parameters of sample size and the time between compression cycles did not significantly influence the texture parameters of TPA, unlike the compression percentage and velocity. The optimum operating region for TPA to better discriminate differences in texture parameters was evaluated. For adhesiveness, a percentage of $75 \%$ compression and a compression speed of 0.23 $\mathrm{mm} \cdot \mathrm{s}$ are recommended to detect differences among the samples for the cohesiveness parameter, while for gumminess and resilience, the use of $15 \%$ compression and $2.59 \mathrm{~mm} \cdot \mathrm{s}$ speed is recommended. In both cases, one must employ the shortest time between two cycles and use a smaller sample size to save both analysis and sample time, respectively. The optimal region for discriminating the parameters of hardness, elasticity and chewiness was not determined for the different preserve samples analyzed. Using the Tukey test at a 5\% significance level, the region with optimized parameters of texture discrimination was determined for the brands studied.

\section{CONFLICT OF INTEREST}

The authors declare that they have no conflict of interest carrying the research and publishing the manuscript.

\section{ACKNOWLEDGEMENTS}

The authors thank the Universidade Federal de Lavras (UFLA) and Universidade Federal de Ouro Preto (UFOP) for the financial supports.

\section{REFERENCES}

Adhikari B, Howes T, Bhandari BR \& Truong V (2001) Stickiness in foods: a review of mechanisms and test methods. International Journal of Food Properties, 4:1-33.

Alvarez MD, Canet W \& Lopez ME (2002) Influence of deformation rate and degree of compression on textural parameters of potato and apple tissues in texture profile analysis. European Food Research and Technology, 215:13-20.

Alves JA, Curi PN, Pio R, Penoni ES, Pasqual M \& Souza VR (2019) Characterization, processing potential and drivers for preference of pepper cultivars in the production of sweet or spicy jellies. Journal of Food Science and Technology-Mysore, 56:624-633

Barrangou LM, Drake MA, Daubert CR \& Foegeding EA (2006) Sensory texture related to large-strain rheological properties of agar/glycerol gels as a model food. Journal of Texture Studies, $37: 241-262$

Besbes S, Drira L, Blecker C, Deroanne C \& Attia H (2009) Adding value to hard date (Phoenix dactylifera L.): composition, functional and sensory characteristics of date jam. Food Chemistry, 112:406-411.

Chen L \& Opara UL (2013) Texture measurement approaches in fresh and processed foods - A review. Food Research International, 51:823-835

Curi PN, Albergaria FC, Pio R, Schiassi, MCEV \& Tavares BS (2019) Characterization and jelly processing potential of different fig cultivars. British Food Journal, 121:1686-1699.

Curi PN, Tavares BS, Almeida AB, Pio R, Pasqual M, Peche PM \& Souza VR (2017) Characterization and influence of subtropical persimmon cultivars on juice and jelly characteristics. Anais da Academia Brasileira de Ciências, 89:1205-1220.

Dobraszczyk BJ (1997) The rheological basis of dough stickiness. Journal of Texture Studies, 28:139-162 
Ferreira DF (2014) Sisvar: a Guide for its Bootstrap procedures in multiple comparisons. Ciência e Agrotecnologia, 38:109-112.

Fogaça DNL, Silna WS \& Rodrigues LB (2017) Influence of compression parameters on mechanical behavior of mozzarella cheese. Journal of Texture Studies, 48:427-432.

Huang Y, Cavinato AG, Tang J, Swanson BC, Lin M \& Rasco BA (2007) Characterization of sol-gel transitions of food hydrocolloids with near infra-red spectroscopy. LWT - Food Science and Technology, 40:1018-1026.

Huson MG \& Maxwell JM (2006) The measurement of resilience with a scanning probe microscope. Polymer Testing, 25 2-11.

International Standard ISO 80000-1 (2009) Quantities and unitsPart 1 general. Geneva, Switzerland: ISO.

Jeguirim SEG, Dhouib AB, Sahnoun M, Cheickrouhou M, Schacher L \& Adolphe D (2010) Sensory and instrumental techniques evaluating the effect of structure parameters on the tactile properties of knitted fabrics. Journal of Texture Studies, 41:714735 .

Peleg M (2019) The instrumental texture profile analysis revisited. Journal of Texture Studies, 50:362-368.

Pereira PAP, Souza VR, Teixeira TR, Queiroz F, Borges SV \& Carneiro JDS (2013) Rheological behavior of functional sugarfree guava preserves: Effect of the addition of salts. Food Hydrocolloids, 31:404-412.
Pereira PAP, Souza VR, Silva AA, Queiroz F, Borges SV, Pinheiro ACM \& Carneiro JDS (2019) Influence of gelling agent concentration on the characteristics of functional sugar-free guava preserves. Emirates Journal of Food and Agriculture, $31: 501-510$

Pons M \& Fiszman SM (1996) Instrumental texture profile analysis with particular reference to gelled systems. Journal of Texture Studies, 27:597-624.

Rosenthal AJ (2010) Texture profile analysis-how important are the parameters? Journal of Texture Studies, 41:672-684.

Schiassi MCEV, Salgado DL, Meirelles BS, Lago AMT, Queiroz F, Curi PN, Pio R \& Souza VR (2019) Berry Jelly: Optimization Through Desirability Based Mixture Design. Journal of Food Science, 84:1522-1528

Souza VR, Pereira PAP, Pinheiro ACM, Lima LCO, Pio R \& Queiroz F (2014) Analysis of the subtropical blackberry cultivar potential in jelly processing. Journal of Food Science, 79:1776-1781.

Szczesniak AS (1963a) Objective measurement of food texture. Journal of Food Science, 28:410-420.

Szczesniak AS (1963b) Classification of textural characteristics. Journal of Food Science, 28:385-389.

Vitti KA, Lima LM \& Martines Filho JG (2020) Agricultural and economic characterization of guava production in Brazil. Revista Brasileira de Fruticultura, 42:e-447. 